сохранения флористического биоразнообразия кальцевых и псаммофитных степных и лесостепных ландшафтов в особо охраняемых природных территориях центральной части Приволжской возвышенности в Ульяновской области //Природа Симбирского Поволжья. Сб. научн. трудов. Вып. 10. Ульяновск, 2009.-С. 108-115.

9. Масленников А.В., Масленникова Л.А. Варваровская степь-эталонное урочище и центр развития кальциевых и псаммофитных ландшафтов Засызранских степей Ульяновского Предволжья // Природа Симбирского Поволжья. Сб. научн. трудов. Вып. 11.- Ульяновск, 2010. C. 58-61.

10. Масленников А.В., Масленникова Л.А. Оценка экологического состояния кальциевых ландшафтов Приволжской возвышенности методами фитомониторинга // XXVI Любищевские чтения. Современные проблемы эволюции. Ульяновск, 2012. С. 237-245.

11. Масленников А.В., Масленникова Л.А. Лесостепные урочища центральной части Приволжской возвышенности-центры сохранения биоразнообразия Среднего Поволжья // Лесостепь Восточной Европы:структура, динамика и охрана. Сборник статей Международной научной конференции, посвященной 140-летию со дня рождения И.И. Спрыгина. Пенза: изд-во ПГУ, 2013. C. 94-96.

12. Мацко В.П. Восстановление почвенно-растительного покрова нарушенных земель Белоруссии $\backslash$ Автореферат на соискание ученой степени кандидата географических наук. Ленинград, 1988. 20 с.

13. Красная книга Ульяновской области / Под науч. ред. Е.А. Артемьевой, О.В. Бородина, М.А. Королькова, Н.С. Ракова; Правительство Ульяновской области. Ульяновск: Изд-во «Артишок», 2008. 508 с.

14. Масленников А.В. О роли адвентивных видовкальцефилов в формировании флоры кальциевых ландшафтов Приволжской возвышенности // Адвентивная и синантропная флора России и стран ближнего зарубежья: состояние и перспективы.-Ижевск: УдГУ, 2006. С. 69-71.

15. Серебряков И.Г. Экологическая морфология растений. М.: Высшая школа, 1962. 378 с.

16. Уиттекер Р. Сообщества и экосистемы. М.: Прогресс, 1980. $326 \mathrm{c}$

17. Масленников А.В., Масленникова Л.А. Сравнительное изучение локальных флор кальциевых ландшафтов-основа сохранения флористического биоразнообразия Приволжской возвышенности // Фундаментальные и прикладные проблемы ботаники в начале XXI века: Материалы XII съезда Русского ботанического общества. Петрозаводск-Часть 4. Сравнительная флористика. Урбанофлоры. Петрозаводск, 2008. С. 76-77.

18. Масленников А.В., Масленникова Л.А. Итоги изучения локальных флор кальциевых и псаммофитных ландшафтов центральной части Приволжской возвышенности // Труды рязанского отделения Русского ботанического общества.-Вып. 2.-Ч. 2.: Сравнительная флористика: м-лы Всерос. Школы-семинара по сравнительной флористике, посвящённой 100-летию «Окской флоры» А.Ф. Флёрова / под. ред. О.Г. Барановой. Рязань, 2010. C. 109-114.

19. Винюсева Г.В. Экологический анализ степного компонента флоры комплексного ландшафтного заказника «Бахтеевские увалы» // Вестник Ульяновской государственной сельскохозяйственной академии. 2014. №3 (27). C. 45-49.

20. Красная книга Российской Федерации (растения и грибы). М. 2008. 782 с.

21. Масленников А.В., Масленникова Л.А. Состояние и перспективы изучения флоры сосудистых растений Ульяновской области // Изучение и охрана флоры Средней России: Материалы VII научного совещания по флоре Средней России (Курск, 29-30 января 2011 г.). Москва, 2011. С. 91-94.

\title{
ENVIRONMENTAL ANALYSIS OF FLORA AND VEGETATION AROUND ABANDONED CHALK UPSTREAM CAREER URBAN SETTLEMENT STARAIA KULATKA
}

\section{(C) 2015}

\author{
G.V. Vinyuseva, post-graduate at the Department of Botany
} Ulyanovsk State Pedagogical University, Ulyanovsk (Russia)

Annotation. The article provides an environmental assessment of the flora of abandoned chalk quarry located in the North-East R. p. Staraia Kulatka Ulyanovsk region, now part of geographically part of the protected areas "Bagaevskii ridges". On the basis of various indicators the analysis of flora: the ratio of life forms on systems K. Raunchier and I. G. Serebryakov, ecological structure, ecological-coenotic analysis, moreover, traces the dynamics of the vegetation and its features at the termination of economic activity. A detailed analysis of the flora showed atalanti this once-transformed human ecosystems and the timeliness of the creation of a protected area, as well as the high ability of vegetation calcium landscapes to recovery.

Plant communities identified capacity of protected and rare species of plants such as: Serratula gmelinii exchange., Adonis vernalis L., Pulsatilla patens (L.)Mill. Subsequent clarification and confirmation requires finding a young plant Schivereckia podolica Andrz. Met an adventive plant quarantine-Cyclachaena xanthifolia (Nutt.) Fresch. and adventive species Ceratocephala testiculata (Crantz) Besser is a new distribution points data of plants for the Ulyanovsk region.

The territory of the abandoned quarry, mining of chalk, may serve as a platform for studies of natural recovery of vegetation after the cessation of economic activity.

Key words: flora; biomorphs; anthropogenic transformation; rare species; adventive species; the impact of chalk mining on the environment.

\section{УДК 581.45}

\section{(C) 2015}

\section{БИОЛОГИЯ ARTEMISIA SANTONICA L. НА СЕВЕРНОЙ ГРАНИЦЕ АРЕАЛА}

Ю.А. Вяль, кандидат биологических наук, доцент кафедры общей биологии и биохимии Пензенский государственный университет, Пенза (Россия)

Н.Г. Мазей, кандидат биологических наук, доцент кафедры общей биологии и биохимии Пензенский государственный университет, Пенза (Россия)

Л.А.Новикова, доктор биологических наук, профессор кафедры общей биологии и биохимии Пензенский государственныии университет, Пенза (Россия)

А.А. Миронова, студентка

Пензенский государственньй университет, Пенза (Россия)

Аннотация. Изучены некоторые фитоценотические и онтогенетические особенности редкого растения Пензенской области полыни сантонинной Artemisia santonica L. (семейство сложноцветные Asteraceae) на северной 
границе ареала в условиях засоления и сильной антропогенной нагрузки. Установлено, что вид на границе ареала способен существовать на засолённых почвах в составе растительных сообществ разнотравных и злаковоосоковых галофильных степей, выступая в роли доминанта и содоминанта. Вид способен осуществлять большой жизненный цикл и удерживать территорию в этих условиях благодаря активизации вегетативного размножения (с помощью корневых отпрысков), которое способствует глубокому омоложению дочерних особей (до имматурного возрастного состояния). Описаны морфометрические признаки особей вегетативного происхождения, принадлежащих к трём возрастным периодам (прегенеративному, генеративному и постгенеративному) и шести онтогенетическим состояниям (имматурному первой подгруппы, имматурному второй подгруппы, виргинильному, генеративному, субсенильному и сенильному); приводятся схематические графические изображения морфологических особенностей особей полыни сантонинной прегенеративного, генеративного и постгенеративного возрастных периодов. Уточнена структура генеративного побега. Выявлено, что соотношение зон возобновления, торможения и синфлоресценции сильно варьирует у разных особей. Выявлены слабая морфологическая дифференциация генеративного периода на молодое, зрелое и старое генеративное состояния, отсутствие признаков нормальной и сенильной партикуляции. Обсуждаются адаптивные возможности выявленных особенностей онтоморфогенеза вида.

Ключевые слова: онтогенез; Artemisia santonica L.; вегетативное размножение; редкие растения; Красная книга.

Artemisia santonica L.-чрезвычайно перспективное растение семейства Asteraceae. Оно привлекает внимание исследователей своими фармакологическими свойствами: благодаря содержанию эфирных масел, сесквитерпеновых лактонов, фенольных и тритерпеновых соединений, полисахаридов, дубильных веществ характеризуется антигельминтными, фунгицидными, антибактериальными, протистоцидными свойствами $[1$, с. $61 ; 2$, с. $20-21 ; 3$, с. $177-179 ; 4$, с. 113-117]. Это хорошее кормовое растение, выносящее значительную пастбищную нагрузку [5, с. 81$]$

Artemisia santonica-это европейско-кавказский вид. В России встречается в степных районах европейской части, в Крыму и на Кавказе; заходит на юго-восток Средней Европы, на северо-запад Средней Азии [6, с. 171]. В пределах ареала вид встречается на солонцах и солончаках, солонцеватых лугах, степных понижениях, по берегам водоёмов, то есть является характерным компонентом галофильно-луговостепной растительности на солонцеватых и солончаковатых почвах в долинах рек, по окраинам озер, лиманов, приморских лугов юга Восточной Европы [6, с. 171; 7, с. 9-10; 8, с. 7-8]. Также растёт по засолённым склонам в нижней части горного пояса [6, с. 171], на меловых рухляках [9, с. 343].

В Пензенской области вид является редким, занесён в региональную Красную книгу с 3 статусом $[10$, с. 44,11, c. 111$]$. На сегодняшний день известно о восьми местообитаниях в Колышлейском, Малосердобинском, Пензенском, Сердобском, Неверкинском районах. Здесь А. santonica встречается по солонцам, засоленным степям и лугам [12, с. $118-119,13$, с. $57-58]$. Вид, находящийся близ северной границы своего ареала, уязвим из-за мелиорации засоленных почв, чрезмерного выпаса скота $[14$, с. 111$]$. Также вид охраняется в Ульяновской области [15, с. 136- 137].

Для разработки рекомендаций по охране вида, возможному введению A. santonica в культуру необходимо изучение особенностей её биологии на границе ареала, что и является целью данной работы.

Материал и методы. Исследования проводились в июле 2014 г. на юго-юго-востоке Пензенской области (на границе с Саратовской областью), в Неверкинском районе, в пределах недавно обнаруженного местообитания А. santonica близ с. Мансуровка («Мансуровский солончак»).

Территория представляет собой своеобразный ландшафт на водоразделе рек Сормино и Карноварский овраг-левых притоков р. Елань-Кадада (левого притока p. Суры) на высоте около 250-260 м над ур. м.

Здесь к поверхности близко подходят минерализованные грунтовые воды, вымывающие соли из соленосных горных пород, в связи с чем получили развитие солончаки и солонцы.

Для геоботанической характеристики растительности с участием A. santonica были заложены 33 пробных площади (размером 4 м²). Описание площадок проводилось по традиционной методике, а их последующая классификация по доминантному принципу.

Для изучения онтогенеза было собрано 50 растений А. santonica разного возрастного состояния. Возрастные состояния выделяли в соответствии с рекомендациями [16, с. 141-149; 17, с. 7-34]. Для уточнения абсолютного возраста растений выполняли поперечные срезы подземных органов.

Результаты и их обсуждение. В условиях «Мансуровского солончака» A. santonica входит в состав растительных сообществ, принадлежащих различным ассоциациям. Наибольшую площадь (37\%), занимают фитоценозы сантониннополынной ассоциации галофильных степей. Общее проективное покрытие (ОПП) колеблется от 43 до 74\%. В этой ассоциации А. santonica может давать от 25 (15) до $45 \%$ проективного покрытия (ПП). Кроме этого, этот вид может участвовать в других разнотравных ассоциациях галофильных степей (на 27\% площади) с доминированием следующих видов: Artemisia pontica L., Galatella villosa (L.) Reichenb. fil., Kochia prostrata (L.) Schrad., Limonium gmelinii (Willd.) O.Kuntze, Silaum silaus (L.) Schinz et Thell. и др. ОПП в разных ассоциациях сильно колеблется от 30 до 70\%, а участие в них A. santonica чаще не превышает $10 \%$ ПП, редко бывает около 20\%. Изучаемый вид принимает также участие в формировании злаковоосоковых ассоциаций галофильных степей (на $36 \%$ площади) c доминированием таких видов, как Bromopsis inermis (Leyss.) Holub, Bromopsis riparia (Rehm.) Holub, Carex supina Willd. ex Wahlenb., Festuca valesiaca Gaudin, Poa angustifolia L., P. distans Jacq., Puccinellia diffusa V.I. Krecz. и др. ОПП в этих ассоциациях также сильно колеблется от 42 до $77 \%$, а ПП А. santonica может быть различным и иногда достигает $15-25 \%$.

Взрослые особи Artemisia santonica на «Мансуровском солончаке» формируют жизненную форму стержнепридаточнокорневого прямостоячего корнеотпрыскового полукустарничка с базисимподиальным возобновлением и моно-дициклическими ортотропными удлинёнными монокарпическими побегами, что согласуется с данными других авторов [18, с. 7].

По особенностям строения синфлоресценции полынь сантонинная на «Мансуровском солончаке» имеет форму Artemisia santonica var. erecta Kell.-корзинки, с верхушкой общего соцветия, направленной вверх, в отличие от A. santonica var. nutans Kell. с опущенными вниз корзинками и ветвями соцветия [19, с. 354-356].

Более 95\% всех изученных особей имеют вегетативное происхождение-сформировались из корневых отпрысков генеративных особей. Высокая активность вегетативного размножения полыни сантонинной на «Мансуровском солончаке» обусловлена антропогенной нагрузкой. Участок регулярно подвергается выпасу и палам. Это затрудняет семенное размножение особей, но стимулирует образование корневых отпрысков, бла- 
годаря которым популяции удаётся поддерживать высокую численность и удерживать территорию. Активизация вегетативного размножения в подобных условиях установлена ранее и для других видов [20, с. 127] пришли к выводу, что, несмотря на значительные различия по габитусу и морфометрическим признакам (высота растений колеблется от 17 до 50 см;

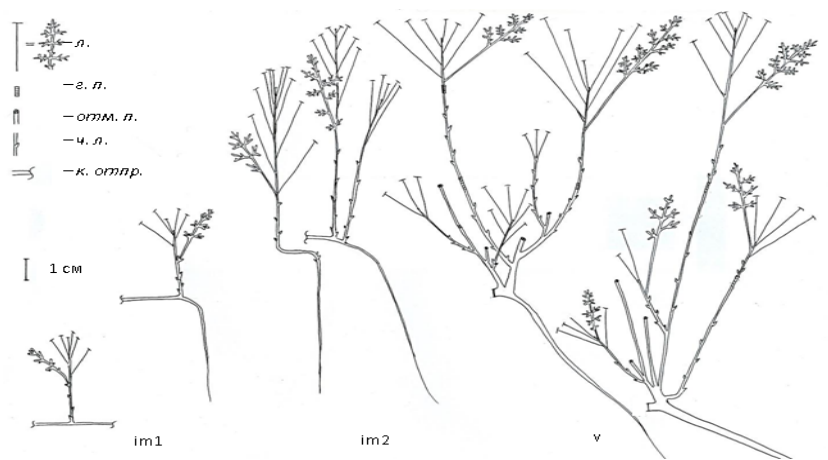

Рисунок 1 - Прегенеративный период

онтогенеза Artemisia santonica L. на «Мансуровском солончаке» (л.-ассимилируюший лист; 2. п.-зона

торможения прошлогоднего годичного побега-граница годичных приростов ди- и трициклических побегов, отм. п.-отмериие побеги; ч. л.-чешуевидный лист и пазушная почка зоны возобновления; к. отпр.-линия

обрыва; показана часть корневого отпрыска)

Имматурные особи второй подгруппы (im2) сохраняют габитус одноосного неветвящегося растения; отличаются от im1-особей размерами-их побеги имеют в 2 раза большую длину от 5,5 до 10 см (в среднем $8,6 \mathrm{cm)}$ за счёт удлинения междоузлий и заложения новых метамеров верхушечной почкой. Увеличиваются в размерах листья, утолщается стебель. Подземная сфера сохраняет полувзрослые черты. Корневой отпрыск, выполняющий функцию «главного» корня заглубляется до 10 и более см, наблюдается его слабое ветвление. Иногда на корневом отпрыске в области изгиба заметны спящие почки. Редко трогается в рост не одна, а две из них, поэтому формирующаяся имматурная особь представлена 2-мя наземными побегами. Возраст большинства im2-особей 2 года. Начало ветвления особей знаменует переход к взрослому-виргинильному возрастному состоянию.

У виргинильных особей трогаются в рост почки в зоне возобновления-наблюдается базипетальное ветвление. Виргинильная особь представляет собой систему из 3-5 побегов: моно-, ди- и (редко) трициклических. Опробковение затрагивает большую часть побегов. Наблюдается значительное утолщение стебля главного побега в основании. В большинстве случаев утрачивается связь с материнским растением за счёт разрушения горизонтального участка корневого отпрыска. Виргинильные особи сами способны формировать корневые отпрыски как в основании корня, так и выше-в основании опробковевшего стволика. Минимальный возраст v-особей-3-4 года. Формирование зоны синфлоресценции свидетельствует о переходе к следующему периоду онтогенезагенеративному (рис. 2).

Исследователи онтогенеза полыни сантонинной указывают на то, что генеративные особи хорошо дифференцируются на 3 возрастных состояния: молодое генеративное (g1); зрелое генеративное $(\mathrm{g} 2)$, когда для растения характерны наибольшие репродуктивные возможности; и старое генеративное (g3) с признаками угнетения, старения и отмирания скелетных осей [7, с. 10-12].

Изучив 15 генеративных особей полыни сантонинной на «Мансуровском солончаке», мы количество цветущих побегов от 1 до 4-х; количество нецветущих побегов от 1 до 7; количество корзинок от 20 до 560), отнесение генеративных особей к одной из трёх групп весьма затруднительно.

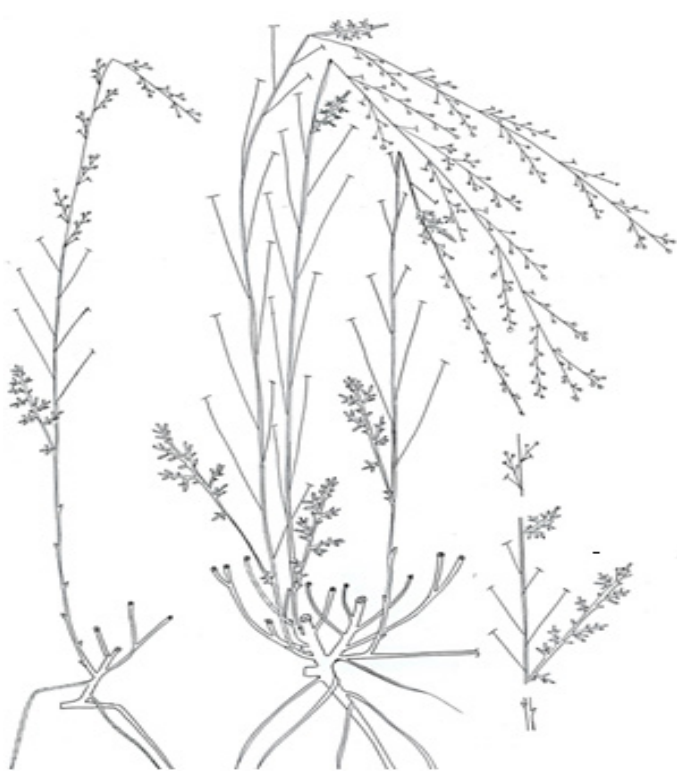

Рисунок 2 - Генеративный период онтогенеза Artemisia santonica L. на «Мансуровском солончаке» (сфл.-синфлоресиениия; з. трм.-зона торможения; з. взб.-зона возобновления)

Большинство из них имеет значительное число отмерших стволиков (число которых часто превосходит число живых побегов), связанных с повреждением растений скотом и пожарами, поэтому о преобладании процессов новообразования или отмирания говорить сложно. В большинстве случаев морфометрические различия растений обусловлены их жизненностью, а не онтогенетическим состоянием. Признаков старческой и нормальной партикуляции, которую отмечали в условиях Калмыкии и Волгоградской области другие исследователи [7, с. 11-12], мы не наблюдали.

Надземная часть генеративных особей представлена в среднем двумя генеративными побегами высотой 24,7 см и тремя вегетативными побегами высотой 5,4 см.

Генеративный побег дифференцирован на 3 зоны: возобновления, торможения и синфлоресценцию. Структура монокарпического побега сильно варьирует. Зона возобновления состоит из 3-9 метамеров (в среднем 5,8 $\pm 0,7$ ), на её долю приходится от 7 до $32 \%$ (в среднем $19,8 \pm 2,1 \%$ ) всей длины побега. Зона торможения образована 4-12 метамерами (в среднем 8,4 $\pm 0,9)$, на её долю приходится от 22 до $58 \%$ (в среднем $37,3 \pm 4,1 \%$ ) длины побега. Синфлоресценция полыни сантониннойэто метёлка из корзинок. На ее долю приходится от 30 до $60 \%$ (в среднем $42,9 \pm 2,8 \%$ ) длины монокарпического побега.

Если судить по строению корня, развившегося из корневого отпрыска, возраст генеративных особей составляет около 6-10 лет.

Постгенеративный период представлен субсенильным и сенильным онтогенетическими состояниями (рис. 3).

Субсенильные особи отличаются небольшим количеством побегов, большинство из которых не несут цветков, а если синфлоресценция и несёт несколько корзинок, то плодов, как правило, не образуется.

В сенильное возрастное состояние могут переходить, видимо, особи всех онтогенетических состояний, в том числе минуя генеративный период. Это происходит при многократном (несколько лет подряд) повреждении побегов и сильном снижении жизненности. 


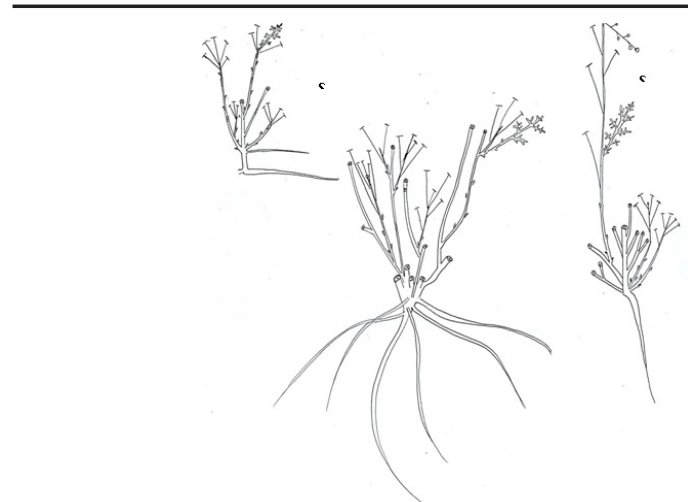

Рисунок 3 - Постгенеративный период онтогенеза Artemisia santonica L. на «Мансуровском солончаке»

Таким образом, сравнение данных по онтогенезу полыни сантонинной в центре ареала [7, с. 10-12] и собственных данных позволило выявить следующие особенности развития этого вида на северной границе ареала при сильной антропогенной нагрузке. Artemisia santonica способна существовать на засолённых почвах в составе растительных сообществ разнотравных и злаковоосоковых галофильных степей, выступая в роли доминанта и содоминанта. Вид способен осуществлять большой жизненный цикл и удерживать территорию в условиях значительного антропогенного пресса благодаря активизации вегетативного размножения. При этом из корневых отпрысков формируются глубоко омоложенные дочерние особи іm1-возрастного состояния. Характерны слабая морфологическая дифференциация генеративного периода на молодое, зрелое и старое генеративное состояния, отсутствие признаков нормальной и сенильной партикуляции (возможно, по причине сокращения продолжительности онтогенеза и выпадения отдельных стадий, например, старого генеративного состояния).

Авторы статьи выражают искреннюю благодарность Владимиру Михайловичу Васюкову за помощь в определении видов, Михаилу Геннадьевичу Щербакову, Олегу Александровичу Полумордвинову, Оксане Евгеньевне Сурковой за помощь в сборе материала.

\section{СПИСОК ЛИТЕРАТУРЫ}

1. Растительные ресурсы СССР. Семейство Asteraceae. СПб: Наука, 1994. С. 61.

2. Водорезова Л.А. Изучение основных групп биологически активных соединений травы полыни сантониковой // Кубанский научный медицинский вестник. 2006. №3-4. С. 20-21.

3. Симагина Н.О. Аллелопатические свойства гликогалофита Artemisia santonica L. // Учёные записки Таврического национального университета имени В.И. Вернадского. Сер. «Биология, химия». 2006. Т. 19 (58). №4. С. 177-185.

4. Симагина Н.О., Глумова Н.В. Фенольные соединения Artemisia santonica L., Halochemum strobilaceum (Pall.) M. Bieb., проявляющие аллелопатическую активность // Учёные записки Таврического национального университета имени В.И. Вернадского. Серия «Биология, химия». 2008. Т. 21 (60). №2. C. 113-160.

5. Шамсутдинов 3.Ш., Савченко И.В., Шамсутдинов Н.3. Галофиты России, их экологическая оценка и использование. М.: РАСХН, 2000. 399 с

6. Леонова Т.Г. Род Artemisia L. // Флора европейской части СССР. Т. VII / Под ред. Н.Н. Цвелёва. СПб: Наука, 1994. C. 171

7. Зенкина Т.Е., Сагалаев В.А. Закономерности онтоморфогенеза полыни сантонийской (Artemisia santonica L.) // Естественные науки. 2013. №3(44). C. 9-15.

8. Зенкина Т.Е., Сагалаев В.А. Особенности формирования пространственной и демографической структуры ценопопуляции полыни сантонийской (Artemisia santonica L., Asteraceae) под воздействием антропогенных факторов // Вестн. Волгоградского гос. ун-та. Сер. 11: Естественные науки. 2013. №2 (6). С. 7-13.

9. Губанов И.А., Киселёва К.В., Новиков В.С., Тихомиров В.Н. Иллюстрированный определитель растений средней полосы России. Т. 3. Покрытосеменные (двудольные: раздельнолепестные). М.: Товарищество научных изданий КМК, Институт технологических исследований, 2004. С. 343.

10. Красная книга Пензенской области. Т. 1. Растения и грибы. Пенза: ИПК «Пензенская правда», 2002. 160 с.

11. Красная книга Пензенской области. Т. 1. Грибы, лишайники, мхи, сосудистые растения. Пенза, 2013. $300 \mathrm{c}$.

12. Солянов А.А. Флора Пензенской области Пенза: ПГПУ им. В.Г. Белинского, 2001. С. 118-119.

13. Васюков В.M. Растения Пензенской области (конспект флоры). Пенза: ПГУ, 2004. С. 57-58.

14 Новикова Л.A. Artemisia santonica L. // Красная книга Пензенской области. Т. 1. Грибы, лишайники, мхи, сосудистые растения. Пенза, 2013. С. 111.

15. Раков Н.C. Artemisia santonica L. // Красная книга Ульяновской области. Ульяновск: Изд-во «Артишок», 2008. C. 136-137.

16. Работнов Т.А. Методы определения возраста и длительности жизни у травянистых растений // Полевая геоботаника. М.-Л.: АН СССР, 1960. Т. 2. С. 141-149.

17. Уранов А.А. Возрастной спектр ценопопуляций как функция времени и энергетических волновых процессов // Биол. науки, 1975. №2. С. 7-34.

18. Беэр А.С. Сравнительное биоморфологическое исследование восточноевропейских представителей рода Artemisia L. (Asteraceae Dumort.): автореф. дисс. ... канд. биол. наук. М.:, 2005. 21 с.

19. Келлер Б.А., Комаров Н.Ф. Полынь приморская // Флора юго-востока европейской части СССР / Под общ. ред. Б.А. Федченко. М.-Л.: Изд-во АН СССР, 1936. C. $354-356$

20. Вяль Ю.А. Мазей Н.Г. Особенности биологии Herminium monorchis (Orchidaceae) в условиях засоления //Фиторазнообразие Восточной Европы. 2014. VIII. 4. C. 114-130. (C) 2015

\section{BIOLOGY OF ARTEMISIA SANTONICA L. ON THE NORTHERN BORDER OF THE AREA}

Y.A. Vyal, Candidate of Biological Sciences, Associate Professor of the Department of General Biology and Biochemistry Penza State University, Penza (Russia)

N.G. Mazey, Candidate of Biological Sciences, Associate Professor of the Department of General Biology and Biochemistry Penza State University, Penza (Russia)

L.A. Novikova, Doctor Of Biological Sciences, Professor of the Department of General Biology and Biochemistry Penza State University, Penza (Russia)

A.A. Mironova, student

Penza State University, Penza (Russia)

Annotation. Peculiarities of ontogenesis and phytosociology of rare plant of Penza region Artemisia santonica Самарский научный вестник. 2015. № 2(11) 
L. (family Asteraceae) on Northern border of area in saline conditions under strong anthropogenic load is studied. Ability of Artemisia santonica to exist at the border area on saline soils in plant association of grassy and halophilic steppe, acting as dominant and codominant is established. Artemisia santonica is able to carry out life cycle and to hold territory because vegetative reproduction, which promotes deep rejuvenation affiliated plants (immature age status). Age status and as well as biometric characteristics of vegetative specimens are described (three age period-virgin, generative, postgeneration; six age status immature-1, immature-2, virgin, generative subsenile); schematic graphical image of morphological features of Artemisia santonica is depicted. Structure of the generative shoot is clarified. Possibility of variability of structure of the generative shoots is identified. Weak morphological differentiation of generative individuals on young, mature and old is identified. Signs of normal and senile particulate are not found. Possibilities of adaptation of Artemisia santonica at level of ontogenesis are discussed.

Keywords: ontogenesis; Artemisia santonica L.; vegetative reproduction, rare plants; Red book.

УДК 581.45

(C) 2015

\section{ОСОБЕННОСТИ ОНТОГЕНЕЗА BASSIA LANIFLORA (S.G. GMEL.) A.J. SCOTT. (CHENOPODIACEAE)}

Ю.А. Вяль, кандидат биологических наук, доцент кафедры общей биологии и биохимии Пензенский государственный университет, Пенза (Россия)

Н.Г. Мазей, кандидат биологических наук, доцент кафедры общей биологии и биохимии Пензенский государственный университет, Пенза (Россия)

Л.А. Новикова, доктор биологических наук, профессор кафедры общей биологии и биохимии Пензенский государственный университет, Пенза (Россия)

А.А. Миронова, студентка

\section{Пензенский государственный университет, Пенза (Россия)}

Аннотация. Изучены фитоценотические и онтогенетические особенности Bassia laniflora (S.G. Gmel.) A.J. Scott (семейство Маревые Chenopodiaceae) на юге Пензенской области на песчаных почвах. Установлено, что бассия шерстистоцветковая встречается в составе разреженных (проективное покрытие не превышает 20-40\%) разнотравных псаммофильных степей с участием тысячелистника благородного Achillea nobilis L., мелколепестника канадского Erigeron canadensis L., щавеля малого Rumex acetosella L. и полыни понтийской Artemisia pontica L, выступая в роли доминанта и содоминанта. Участие Bassia laniflora составляет от 1 до $15 \%$. Описаны морфометрические признаки особей, принадлежащих к двум возрастным периодам и пяти онтогенетическим состояниям: прегенеративному (проростки, ювенильные, имматурные, виргинильные особи) и генеративному (генеративные особи). Установлена полиморфность особей, особенно ярко выраженная у виргинильных и генеративных растений. Виргинильные и генеративные особи разделены на три группы по комплексу морфологических признаков, отражающих особенности биоморфы (высота побега, диаметр стебля, особенности ветвления, количество цветков). Приводятся фотографии генеративных особей разных биоморф. Обсуждаются причины полиморфизма особей бассии шерстистоцветковой и его приспособительные возможности в связи с особенностями существования в условиях псаммофильных степей.

Ключевые слова: онтогенез; Bassia laniflora; полиморфность; псаммофит.

Bassia laniflora (S.G. Gmel.) A.J. Scott. (синонимKochia laniflora (S.G. Gmel.) Borb.) относительно слабо изученное растение семейства Маревые (Chenopodiaceae). Растение весьма перспективно как закрепитель песков, индикатор пастбищной дигрессии, кормовое пастбищное растение [1, с. 117-122]. Близкие виды активно изучаются в фармакологическом аспекте, так как содержат тритерпеноиды, стероиды, алкалоиды, обладающие гиполипидемическими [2, с. 877-882], антиаллергическими, противовоспалительными, аналгезирующими [3, с. 1231-1233], гипотензивными и другими свойствами [4, с. 134-137; 5, с. 116-126].

Bassia laniflora-это однолетнее травянистое растение. Данные о высоте побега варьируются у разных авторов: от 5-25 (до 40) см [6, с. 102] и до 50-70 (100) см [7, с. 306]. Побег ветвится в базальной части («растопыренно-ветвистое растение»), побеги тонкие, красноватые, приподнимающиеся или лежачие, покрытые курчавыми короткими волосками, особенно в верхней части [8, с. 130-131]. Листья нитевидные или линейно-нитевидные, толстоватые, на поперечном срезе полукруглые -(полу)вальковатые, шелковисто опушённые, с олиственными укороченными веточками в пазухах. Длина нижних листьев-до 3 см, остальных-до 1,0-1,5 см. Соцветие колосовидное, длинное, прерывистое, из «клубочков», состоящих из $1-3[6$, с. 102] до 2-5 [7, с. 306] цветков. При основании «клубочка» часто имеется пучок длинных волосков.

Цветки обоеполые, пятичленные. Околоцветник с длинными шелковистыми волосками, давшими видовой эпитет. Листочки околоцветника развивают при плодах у своей середины крыловидные выросты (белого цвета с тёмными жилками) диаметром 3-5,5 (6,5) мм. Пыльники длиной 0,7-1,3 мм. Плоды диаметром 1,5-2,0 мм. Цветёт с мая по сентябрь, плодоносит с июня.

Растёт на песках: на аллювиальных наносах в поймах рек, по песчаным степям, разреженным борам, опушкам сосновых лесов, песчаным железнодорожным насыпям, иногда на мелах и мергелях; от лесостепи до полупустынь. Крайний северный предел совпадает с южной границей подзоны широколиственных лесов. Первичный ареал вида располагается в степной зоне. Общее распространение: Казахстан, Южная Сибирь, Кавказ, Северо-Запад Центральной Азии, Малая Азия, Средняя и Южная Европа. В России вид встречается в Астраханской области, Башкирии, Белгородской, Брянской, Волгоградской, Воронежской областях, Калмыкии, Краснодарском крае, Курской, Липецкой, Пензенской, Оренбургской, Ростовской, Рязанской, Самарской, Саратовской, Тамбовской областях, в республике Татарстан, в Ульяновской области. Как редкое заносное растение, отмечено в Ленинградской, Московской, Нижегородской, Тульской области [7, с. 306].

В Пензенской области бассия шерстистоцветковая встречается по берегам рек, на лугах, в степях, преимущественно на песчаной почве, чаще по железнодорожным путям [9, с. 98]; отмечена на разбитых зарастающих песках, в сухих сосновых лесах [10, с. 45].

Материал и методы исследования. Исследования проводились в 3-й декаде июля 2014 года (с 21 по 25 июля) в Неверкинском районе Пензенской области 